\title{
Analysis of Work Life Balance of Female Nurses in Hospitals - Comparative Study between Government and Private Hospital in Chennai, TN., India
}

\author{
K. Santhana Lakshmi, T. Ramachandran, and David Boohene
}

\begin{abstract}
Career women are challenged by work and family commitment at the end of each day in Government and private hospital. Majority of women are working through-out week and $53 \%$ are struggling to achieve work-life balance. Women reported that their life has become a juggling act as they have to shoulder multiple responsibilities at work and home. Both government and private hospital management need to be conscious of this status of female nurses and periodically review their status. They can create supportive environment to help these women achieve work life balance. This article highlights the issues connected with work life balance of female nurses in government and private hospital and the factors that determine work life balance.
\end{abstract}

Index Terms-Imbalance, motivation, rewards, stress, work/life.

\section{INTRODUCTION}

\section{A. Health Care Industry - An Overview}

As the saying goes - "Health is Wealth", health is considered as the most important phenomenon in today's world which determines the wealth of the country at large. The health care industry in India is one of the largest economic and fastest growing professions. In order to create a balance between the provision and reception of health care, various strategies have been worked out which makes the industry effectively by health consciousness among people $\&$ welfare schemes [1]. Nurses play the major role in health care industry and are the first ones who are thought about when we talk about health care and thus it is necessary that their needs have to be taken care and a congenial atmosphere is created for them to work with utmost job satisfaction and content, the result of which would be a high quality nursing care.

\section{B. Work Life Enhancement}

Its concept revolves around three main categories - the work and family, life satisfaction and job satisfaction. This triangle has to be entangled by high level of positive waves which is of great importance in achieving the personal and professional objectives effectively and efficiently Head, D. (2010), April 30 [2]. Studies have proven that factors like improper work-life balance, work pressure, improper working environment, growth pressure, and salary and job

Manuscript received February 21, 2012; revised May 10, 2012.

K. Santhana Lakshmi and T. Ramachandran are with School of Management, SRM University, Kattankulathur (email:boohenedavid@yahoo.com).

D. Boohene is with Business Administration Dept., All Nations University College, Ghana-KF1908(e-mail:anju_laxvis@yahoo.co.in) security have greater impact on job satisfaction. The job satisfaction of a nurse is absolutely important for the smooth functioning and successful upcoming of the health care industry [3].

\section{Nurses in Demand \& Retention Strategies}

The demand for nurses is also increasing not only because of the attractive salary and job security but also because of the care they provide thus making a difference in others lives which is generally not found in many other careers [4]. The role of nurses has expanded from a health care provider to health educator, diagnostic assistant, post care supporter, Health advisor, Physicians Assistant, Operation Theatre Assistant, Health Counselor, Follow up, Health promoter, Administrator, Health researcher, Provide appropriate reassurance to patients and family members, Health Supervisor, Maintenance of Health Reports, Records $\&$ Documents. Other reasons for slowing down of the nurses population is mental stress and work pressure which leads to dissatisfaction. Factors that lead to mental stress and work pressure are improper work life balance, physical health or fitness, improper working conditions, discrimination, distrust and unlimited work load, [5]. Emigration is also considered as a contributing factor to the increasing demand for nurses [6]

\section{A Comparitive Study-Nurses in Government Hospital} Vs Private Hospitals

\section{1) Government Nurses}

The major benefits of a government nurse are Monetary benefits, Job Security, Job Satisfaction More exposure and more experience. Disadvantages of working in government hospitals are Long working hours and Shortages of resources.

\section{2) Private Nurses}

The major benefits of a nurse in private hospital are Better technology and Multi tasking. The disadvantages are that their salary is comparatively lesser than that of the government nurses. Moreover, their exposure to cases is limited due to limited strength of patients [7]

\section{E. Best practices yield best results:}

The management needs to assess the causes for improper work-life balance and lay down strategies to overcome those hurdles and make the nurse productive Ross, C. (2010) [8]. Issues related to work pressure, longer working hours, harassment etc can be addressed by introducing flexi-timing, job rotation, career growth, family get-together, children school funds, child care centres etc, which will motivate the employees to work at place and give their $100 \%$ to their job 
[9].

\section{F. Good Work Life Balance through Management Support}

When the management provides healthy practices on work-life balance, the outcome of health care provided is also healthy [10]. The management support, is also an indicator for favourable treatment, patient satisfaction, employess satisfaction and long term success of the hospital Availability of good work life balance leads to increased intake of skilled nurses, reduces turnover, increases job satisfaction level, commitment, dedication and positive health care provisions at large [11]. WLB related wellness activities are Training \& development programs, health awareness programs, soft skill programs like stress management, conflict mgmt., leadership skills, workshops on talent technologies in medicine, work-life balance workshops can be introduced [12].

\section{REVIEW OF LITERATURE}

Writing about stress in correctional officers, Griffin, Hogan, Lambert, Tucker-Gail \& Baker (2010) defined job stress "as a worker's feelings of job-related tension, anxiety, frustration, worry, emotional exhaustion, and distress" [1].

According to Day (2010), "approximately 50 percent of Nova Scotians reported some work-family conflict, and 25 percent of Canadians experienced high levels of workfamily conflict" [3].

Griffin, Hogan, Lambert, Tucker-Gail and Baker (2010) defined job stress "as a worker's feelings of job-related tension, anxiety, frustration, worry, emotional exhaustion, and distress" [1].

Lambert, Hogan, and Altheimer (2010) defined burnout as a "syndrome where the worker experiences emotional exhaustion, depersonalization, and a reduced sense of personal accomplishment [5].

Robroek et al. (2009), Research shows that women are generally more likely to participate in worksite wellness programs than men and, overall, married employees have much higher participation rates than their single co-workers. Other determinants of higher participation rates include: white-collar or secured contract employees, full-time employees, older age, and small company employees; shift workers, lower income, and less education displayed much lower participation rates. (p. 150)

Neates (2010) writes that the survey revealed that the main obstacles to officer wellness were; (a) structural barriers (e.g., dilapidated office space, below-standard gymnasiums and poor quality exercise equipment), (b) managerial barriers, including shift work, a poor work-life balance, a high volume of work, irregular breaks, and staff shortages, and; (c) cultural barriers (e.g., officers mocking healthy behaviours and seeing employees who sought help as "weak") [4].

Previously, the female workforce in India was mainly employed in non-managerial, subordinate or low-profile positions. Now, they occupy almost all categories of positions in the workplace. (Mathew \& Panchanatham 2009a; 2009b). According to Peeters, Montgomery, Bakker and Schaufeli (2005), pressures from the job and family domains are often incompatible, giving rise to imbalance.

Texas Quick, an expert witness at trials of companies who were accused of overworking their employees, states that "when people get worked beyond their capacity, companies pay the price." (2010) Although some employers believe that workers should reduce their own stress by simplifying their lives and making a better effort to care for their health, most experts feel that the chief responsibility for reducing stress should be management [1].

According to experts (2010) are, in addition to the ultra hard-working and the perfectionist, the loner, the grim and the thin-skinned, especially endangered of a burnout. All together they usually have a lack of a healthy distance to work [8] [10] [12].

\section{RESEARCH QUESTIONS}

When women go for employment either in govt. or private organisation, they add a dimension to their challenge. When they are married they have to take care of the dependents children and adults [in-laws]. When they go for employment, they have to also balance their role between institution and the family. Often the work environment working hours, career opportunities, stress in job \& Family, reward factors at the work place, etc. affect their efforts to balance their work life. Employed married women therefore undertake multiple roles and work life balance becomes a challenge. Added to this, they have to work towards their professional improvement which adds to their work pressure. Hence, in this study analyse,

- Is there any significant difference between the WLB among the female nurses in Government hospital and Private hospital of Chennai city?

- What are the aspects of WLB that led to a better WLB of the employees in the government and private hospital?

\section{OBjectives Of THE StUdy}

1. To identify the influence of work place environment and stress related issues on the emotional status of female nurses.

2. To analyse the features of motivation initiatives adopted by the hospitals.

3. To examine the factors which determine the satisfaction of female nurses.

\section{RESEARCH METHODOLOY}

Research design proposed for the study is 'Descriptive' type of research service. This type of research deals with quality of responses from the respondents, attitudes, interests, technical skills, experience, behavioral, beliefs and values, emotions, personality, self concept etc. Primary data was collected through survey method using questionnaire as the tool. The questionnaire was pre-tested before being finalized and administered. Secondary data was collected from journals and Research articles. 


\section{PERIOD OF THE STUdY}

The objectives set for the study required collection of primary data from the female nurses in Government and Private Hospital. Therefore a questionnaire was drafted, field tested [pilot study] and then finalized. The survey was conducted during January- March'12. The primary data was collected by distributing questionnaire among the female nurses belonging to different dept. of Govt. \& Pvt. Hospitals in Chennai District, Tamiln.adu, India.

\section{SAMPLE}

Primary data was collected from the female nurses of ESI Government Hospital \& Vijaya Hospital, Chennai, Tamil nadu, India. Totally there are about 400 women employees in both ESI government \& Vijaya private hospital of Chennai city. Of this the 200 women nurses belonging to different departments of Medical, surgery, OP and ICU with different background were selected. Questionnaire was distributed to the female nurses belonging to various departments.

\section{LIMITATIONS}

This study was undertaken only among women employees of ESI government \& Vijaya private hospital of Chennai city and so conclusions arrived at based on this study need to be placed in proper perspective before application elsewhere. Another limitation is that since the sample size is only 200 , comparative study to ascertain whether women in different dept.-Medical, surgery, OP and ICU in government and private hospital, face different challenges in balancing their work life.

\section{SCOPE FOR FUtURE RESEARCH}

This type of study could be undertaken among both government and private hospital of different certain common departments like Medical, surgery, OP and ICU, so as to get a more broader picture about work life balance among women in such departments of hospital.

\section{ANALYSIS AND RESUltS}

We have used SPSS as statistical software for the analysis and interpretation of data. We have employed statistical tools like Multiple regression and T-test. We have employed the methods of multiple regression as a tool to find out that how for satisfactory and stress factors are influencing WLB variables. In this analysis dependent variables are classified in terms of Stress \& Satisfactory. And independent variables are undertaken in terms of female nurses demographic profile, work place, stress, motivation \& other benefits and also their personal satisfaction. Stress index was calculated applying weighted score methodology with factors which caused stress, causes for imbalance in work as well as personal life. In the same way satisfactory index was calculated in terms of the factors which influenced satisfaction level including environment in work as well as personal life.
The objective 1 set for this study is supported by the analysis by constructing stress index and satisfaction index. This analysis is carried out separately for nurses in government hospitals and private hospitals

\section{A. Stress Index}

As a number of factors influence the stress level of female nurses in government hospitals, to identify the determinants which influence the stress level, multiple regression technique is used. Seventeen factors are included as independent variables and stress index is taken as the dependent variable.

$$
\begin{aligned}
& \text { 1) Stress Related Influencing Factors (Govt.) } \\
& \mathrm{Y}_{\text {Stress index }}=4.848+0.346^{\mathrm{ns}} \text { Age }-0.148^{\mathrm{ns}} \text { Dept. } \\
& \text { (1.230) (-0.439) } \\
& +1.291{ }^{\mathrm{ns}} \text { Marital-0.160 }{ }^{\mathrm{ns}} \text { Yrs pract- } 1.513^{\mathrm{ns}} \text { TmetkcarPat } \\
& \text { (1.231) (-0.665) (-1.579) }
\end{aligned}
$$
(3.377) (0.369)
$(2.010)+1.384 *$ Ppl dpnt-

$0.002^{\text {ns }}$ Childcre $+2.915^{*}$ Job strs
(4.513)
$(-0.007)$
(2.957)

$+2.878^{*}$ ConflctTm+1.214* Dif.wrkwitDrs- $0.252^{\mathrm{ns}} \mathrm{Undr} \mathrm{rl}$

(4.616)

(4.540) (-0.781)

$-0.837 *$ Chlng ptn isu $+1.180 *$ Drs\&staf apprc

$(-2.527)$

$+1.407 *$ Tm undrstnd

(5.025)

$\mathbf{R}^{2}=0.862, \mathbf{F}=\mathbf{2 8 . 1 0 0}$, * - Significant at $5 \%$ level,

ns - not significant, Fig. in ( ) are ' $t$ ' values

The regression equation fitted for identifying the determinants of stress among nurses in government hospital had an $r^{2}$ value of 0.862 , implying that the dependent variables included in the equation together explained 86 per cent of the variation in stress. This was also found to be statistically significant as confirmed by the significant $F$ value. Among the independent variables, if senior's behavior is not favorable to them, their stress goes up by 0.991 units. If nurses are affected by stress, the level goes up by1.322 units. Even those who have children and adults in their family, stress is also bound to go up by 1.384 units. Whenever there is a conflict amongst their team members, the stress level goes up by 2.878 units. It was found that their stress rises by 1.214 while working with doctors. It was also found that their stress level would come down by 0.837 units, when they successfully handled patient related issues. When doctors and other senior staff did not appreciate their contribution in the existing team, this would add to their stress by 1.180 units. Also, if the other team members failed to understand their needs, they would lose their interest to work and due to this their stress goes up by 1.407 units.

2) Stress Related Influencing Factors (Pvt.)

It is normally presumed that female nurses in private hospitals undergo more stress than their counterpart in government hospital. To examine whether this is true or not, the same independent variables and dependent variables used for the female nurses in government hospitals are used in a multiple regression equation.

$$
\begin{gathered}
Y_{\text {Stress index }}=14.627+0.140^{\mathrm{ns}} \text { Age }-0.392^{\mathrm{ns}} \text { Dept } \\
(0.234)(-0.920) \\
+0.165^{\mathrm{ns}} \text { Marital-1.493 }{ }^{*} \text { Yrs of practice } \\
(0.180) \quad(-3.249)
\end{gathered}
$$


$+2.175 *$ TimtkcarePatint $+1.043 *$ Sr.Behavr (2.256) (3.632)

$+1.412^{*}$ WrkComunity $+1.544^{\text {ns }}$ Stress in family

$$
\text { (4.154) (1.659) }
$$

$+0.362^{\text {ns }}$ Pldpnt $+0.452^{\text {ns }}$ Chldcar $+0.532^{\text {ns }}$ Jobstres

(1.310) (1.574) (0.751)

$+0.410{ }^{\text {ns }}$ ConfltTm $-0.226{ }^{\text {ns }}$ Dif.wrk witDrs

$$
(1.504) \quad(-0.863)
$$

$-1.090^{*}$ AllUndrdrole $+1.585^{*}$ Chalng ptint isu

$$
(-3.324) \quad(4.352)
$$

$+1.254 *$ Drs\&staf aprc. $-0.057^{\text {ns }}$ Tmundrstnd

$$
\text { (3.413) (-0.147) }
$$

$\mathbf{R}^{2}=0.820, \mathbf{F}=\mathbf{2 1 . 9 8 7 ,} *$ - Significant at $5 \%$ level, $\mathbf{n s}-$ not significant, Fig. in ( ) are 't' values

The regression equation fitted for identifying the determinants of stress among nurses in private hospital had an $r^{2}$ value of 0.820 , implying that the dependent variables included in the equation explained 82 per cent of the variation in stress. This was also found to be statistically significant as confirmed by the significant $F$ value. Among the independent variables, years of practice turned out to be statistically significant and a unit increase in years of experience would bring down the stress by about 1.493 units. This is also logically correct as with more experience; the nurses would learn to manage stress better, compared to nurses with no or few years of experience. Next, it could be noted that when the time taken for patient care goes up by a unit, the stress level also goes up by 2.175 units. As regards to behavior of seniors, when they don't behave favorably, the stress goes up by 1.043 units. When nurses in a department have to work in union with those in other departments, the stress goes up by 1.412 units, especially when there is lack of cohesion among the different teams. In continuation to this, it is also observed when there is perfect understanding among the other employees about the role of a nurse; the stress would come down by 1.09 units. Whenever nurses challenge the patient related issues with others, the stress level would go up by 1.585 units. Appreciation of nurses by doctors and other staff add to their stress [by about 1.254 units] as they have an urge to continuously perform well.

\section{B. Satisfaction Index}

Job satisfaction is considered as the powerful motivators. But this is subjected to several factors. Whether the nurses in government hospitals have satisfaction in their job is examined by using multiple regression with satisfaction index as the dependent variable and 23 independent variables.

1) Satisfaction Related Influencing Factors (Govt.) $\mathrm{X}_{\text {Satisfaction index }}=0.080-0.505^{*}$ Age $-0.040^{\text {ns }}$ Dept.

$$
\text { (1.237) }
$$

$+0.806^{\mathrm{ns}}$ Mrital $+0.025^{\mathrm{ns}}$ Yrs of practice

$(-2.822) \quad(-0.195)$

$+0.433^{\mathrm{ns}}$ Tim tkcarPatnt $+0.263^{\mathrm{ns}} \mathrm{Sr}$.Behavr

$$
\text { (0.638) (1.126) }
$$

$-0.045^{\text {ns }}$ WrkComuty $+0.408^{\text {ns }}$ Strsfmly $+0.356^{\text {ns }} P$ pl dpnt

$$
(-0.199) \quad(0.812) \quad(1.503)
$$

$+0.536^{*}$ Chld cre $+1.781^{*}$ Job strs $+2.552^{*}$ ConflictTm

(2.465) (2.074) (4.168)

$+0.550^{*}$ DifwrkwitDrs- $0.125^{\mathrm{ns}}$ Slary

$$
\text { (3.323) (0.1107) }
$$

$-0.418 *$ Chlng patnt isu $+0.633 *$ Drs\&stafaprc

$(-1.871) \quad(2.457)$

$+0.773^{*}$ Tm undrtnd-1.276* Btrotr dpt

(3.843) (-1.738)

$+1.075^{\text {ns }}$ Fits needs $+2.141 *$ am rwrd- $1.009{ }^{\text {ns }}$ Lrn tech

(1.227) (3.689) (-1.110)

$+0.928^{*}$ CarOpp $+0.110^{\text {ns }}$ All undrstnd $+0.426{ }^{\text {ns }}$ Rewrds
(4.898)
$(0.837)$
(0.546)

$-0.086{ }^{\text {ns }}$ Otr.motiv- $0.028{ }^{\text {ns }}$ Anul lv $+0.182{ }^{\text {ns }}$ Cr Brk lv

$(-1.459) \quad(-0.107) \quad(0.482)$

$+0.612^{*}$ Flx hrs $+0.173{ }^{\mathrm{ns}}$ Lv Elct $+0.013^{\mathrm{ns}}$ Witns curt

(1.841) (0.527) (0.064)

$+1.162 *$ Mrige lv- $0.448 *$ Mtrnty lv $+0.609 *$ Exm lv

(3.158) (-1.296) (1.834)

$+0.07^{\mathrm{ns}}$ Tng lv $+0.296^{\mathrm{ns}}$ Stf cnslng $+0.597^{\mathrm{ns}}$ Psy unt
(0.471)
(1.217)

$+0.892 *$ Wrkplc hlth prg $-0.795^{\text {ns }}$ Scol clb

(1.736) (-1.264)

$-0.634{ }^{\text {ns }}$ PreRtrmn- $0.404{ }^{\text {ns }}$ Wmn ntwrk $+0.910 *$ Brst feed

$(-1.404) \quad(-0.706) \quad(2.012)$

$+2.682 *$ Ovrall stis $+0.041{ }^{\mathrm{ns}}$ Sicklv $+0.522 *$ Salary

(4.301) (0.161) (3.028)

$\mathbf{R}^{2}=0.979, \mathrm{~F}=62.462, *$ - Significant at $5 \%$ level, $\mathrm{ns}-$

not significant, Fig. in ( ) are ' $t$ ' values

The regression equation fitted for identifying the determinants of satisfaction among nurses in government hospital had an $r^{2}$ value of 0.979 , implying that the dependent variables included in the equation together explained 98 per cent of the variation in satisfactory level. This was also found to be statistically significant as confirmed by the significant $F$ value. Among the independent variables, it is observed that when young age group nurses are not completely satisfied with their profession, their satisfaction level comes down by 0.505 units. Nurses have stated that they are satisfied about their child care responsibility, because it is shared equally or most of the responsibility is handled by their husband. So their satisfaction goes up by 0.536 units. As they do not have any job related stress, their satisfaction level goes up by 1.781 units. It is found that nurses maintained cordial relationships with their team members without any conflicts, and their satisfaction goes up by 2.552 units. While working with doctors, their satisfaction goes up by 0.550 units. Under certain circumstances, when they failed to handle patient related issues, their satisfactory level would come down by 0.418 units. Also when the nurses have been appreciated by doctors and other staff, it produces more satisfaction, specified by 0.633 units. In continuation to this, when nurses roles and needs have been recognized by other staff members, their satisfaction level would go up by 0.773 units. When nurses are less satisfied in their department, they prefer to work in other departments; and their satisfaction level comes down by 1.276 units. Most of the nurses are being rewarded and feel motivated to perform the work as expected; their satisfaction goes up by 2.141 units. The nurses utilize available career opportunities and training programs and feel motivated, thus their satisfaction level goes up by 0.928 units. They are satisfied with the available work life options, especially with their flexi working hours, and their satisfaction level goes up by 0.612 units, by 1.162 units due to marriage leave allowances, by 0.609 units due to exam leave allowances and in the same way they are 
satisfied with the organizational support in their workplace, satisfaction goes up by 0.892 units and also by 0.910 units in terms of breast feeding support group. But it is noted that they are having issues by availing maternity leave benefit in which satisfactory level comes down by 0.448 units. They are satisfied with their current salary, and so the level goes up by 0.522 units. It is observed that 2.682 units is their overall satisfaction level, about their nursing profession.

2) Satisfactory Related Influencing Factors (Pvt.)

As already pointed out it is of interest to assess whether the female nurses in private hospitals are better positioned in their satisfaction level compared to the female nurses in government hospitals. Hence the same set of dependent and independent variables used for the female nurses government hospitals are applied to determine the satisfaction level of the female nurses in private hospitals.

$$
\mathrm{X}_{\text {Satisfaction index }}=2.378-1.239^{*} \text { Age }+0.210^{\mathrm{ns}} \mathrm{Dept}
$$

$$
(-3.464) \quad(0.826)
$$

$+0.630^{\mathrm{ns}} \mathrm{Martl}+0.809^{*}$ Yrs practice- $0.129^{\mathrm{ns}}$ TimtkcarPtnt

$$
\text { (0.962) (2.607) (-3.193) }
$$

$+0.719^{*}$ Sr.Bhavr $+0.392^{*}$ WrkComty $+2.271{ }^{*}$ Strsfmly

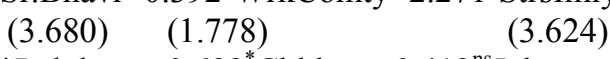

$+0.657 *$ Ppl depnt $+0.688^{*}$ Chld car $+0.412^{\text {ns }}$ Job strs

(5.211) (4.259)

(1.027)

$+0.430 *$ CnflctTm $+0.535^{*}$ Dif.wrkwith Dr- $0.230^{\text {ns }}$ Slry

$$
\text { (2.085) (4.968) (-1.008) }
$$

$+0.734 *$ Chalnge patnt issue $+0.997 *$ Drs\&staff apprc.

$$
\text { (3.156) }
$$

$+0.658^{\text {ns }}$ Tmundrstnd $-0.813 *$ Btr dpt- $0.327^{\text {ns }}$ Fits needs

$$
\text { (2.734) (-2.004) (-0.492) }
$$

$+1.195^{*}$ am rwrd $+0.235^{\text {ns }}$ Lrn tech $+0.670 *$ CarOpp
(1.974)
$(0.365)$
(2.233)

$+0.110{ }^{\text {ns }}$ All undrstnd $+0.286{ }^{\text {ns }}$ Anul lv $+0.390{ }^{\text {ns }}$ Cr. Brk lv

$$
\text { (0.837) (1.167) (0.784) }
$$

$+0.963{ }^{*}$ Flx hrs $+0.794 *$ Lv Elct $-0.067^{\mathrm{ns}}$ Witns curt

$$
\text { (2.154) (2.181) (-0.141) }
$$

$+0.598^{\mathrm{ns}}$ Mrige lv $+0.198^{\mathrm{ns}}$ Mtrnty lv $+0.559{ }^{\mathrm{ns}}$ Exm lv
(1.452)
(1.302)
(1.151)

$+1.389 *$ Tng lv $+0.973^{*}$ Stfcnslng $+1.373 *$ Psy unt

$$
\text { (2.220) (2.097) (2.376) }
$$

$+0.706^{*}$ Wrkplchlth prg $+1.354^{*}$ Sco clb- $1.715^{*}$ Pre Rtrmn

$$
\begin{array}{lll}
(2.577) & (2.999) & (-2.765)
\end{array}
$$

$+0.448^{\mathrm{ns}}$ Wmn ntwrk $+0.149^{\mathrm{ns}}$ Brstfeed

$$
\text { (0.990) (0.361) }
$$

$+0.566{ }^{\mathrm{ns}}$ Ovrall stis $+0.434{ }^{\mathrm{ns}} \mathrm{Siklv}$
(0.936)
(0.709)

$R^{2}=0.979, F=67.256, *$ - Significant at $5 \%$ level, ns -

\section{not significant, Fig. in ( ) are ' $t$ ' values}

The regression equation fitted for identifying the determinants of satisfaction among nurses in private hospital had an $r^{2}$ value of 0.979 , implying that the dependent variables included in the equation together explained 98 per cent of the variation in satisfactory level. This was also found to be statistically significant as confirmed by the significant $F$ value. Among the independent variables, it is observed that when young age group nurses are not completely satisfied with their profession, their satisfaction level comes down by 1.239 units. Nurses, who had more experience in the field, had higher satisfaction levels and it goes up by 0.809 units. When the behaviour of seniors was favorable, their satisfaction level goes up by 0.719 units. When nurses are belonged to better working community, they are satisfied, and the level goes up by 0.392 units. Due to stress free family environment their satisfactory level goes up by 2.271 units. Furthermore, as they did not face any problem in handling their dependents, their satisfaction level goes up by 0.657 units. Also they used to share their child care responsibility with their husbands, thus their satisfaction level goes up by 0.688 units. As they maintained cordial relationship with their other team members; their satisfaction goes up by 0.430 units. It was shown that when nurses did not have any difficulties while working with doctors, their satisfaction goes up by 0.535 units. When nurses handled patient related issues efficiently, their satisfaction level would go up by 0.734 units. Nurses are being appreciated by doctors and other staff, which added to their satisfaction phenomenon by about 0.997 units. When nurses have less satisfaction in their department, they prefer to work better in other departments, and their satisfaction comes down by 0.813 units. Female nurses have been rewarded in such a way that they feel motivated to perform the work expected, and their satisfaction goes up by1.195 units. Also the nurses satisfaction goes up by 0.670 units, because they have been provided with career opportunities and training programs. They are having flexible working hours, and so their satisfactory level goes up by 0.963 units. They avail elective representative leave; it leads them to be satisfied by 0.794 units. They are satisfied by availing training leave, and are indicated by 1.389 units. They found satisfaction in terms of organizational support in workplace health promotion by 0.706 units and by 0.973 units in terms of organizational support in staff counseling, by 1.373 units in terms of organizational support in psychology unit, by 1.354 units in terms of social club, but their satisfaction level comes down by 1.715 units due to non availability of pre-retirement club.

\section{WLB of Female Nurses Comparison Between Govt. \& Pvt Hospital}

$\mathrm{T}$-Test was conducted among the independent samples to ascertain whether the stress level of female nurse who working in both government \& private hospitals, the result (0.853) indicates that there is no significance difference among nurses. And also the satisfactory level of female nurse who are all working in both the government $\&$ private hospitals, the result $(0.883)$ indicates that there is no significance difference among nurses.

\section{Suggestion}

Based on the above conducted regression \& T-test, suggested that both government hospital and $\mathrm{pr}$ ivate hospital needs to closely monitor towards the level of all factors regarding their demographic, work place, stress, motivation and other benefits will improve their quality of work life which in turn will give satisfaction in their personal life.

\section{CONCLUSIONS}

From the above discussion, it is reasonable to conclude that both government and private hospitals in Chennai 
district, should address the Work Life Balance related issues and to support the female nurses to manage their work life balance which would add to the performance of these staff members. The results also indicated that both government and private hospital nurse's the work life balance is a challengeable one. Their need to be a periodical review in terms of their work and personal life satisfaction, otherwise, they would be subjected to severe stress.

\section{REFERENCE}

[1] M. L. Griffin, N. L. Hogan, E. G. Lambert, K. A. Tucker-Gail, and D. N. Baker, "Job involvement, job stress, job satisfaction, and organizational commitment and the burnout of correctional staff," Criminal Justice and Behavior, vol. 37, no. 2, pp. 239-255, 2010.

[2] D. Head, "Employee and workplace wellness matters," E-mail communication, April 30, 2010.

[3] A. Day, "Workplace health and well-being," RCMP Gazette, vol. 72, no. 1 , pp. 18-19, 2010.

[4] M. Neates, "Fit for LIFE at the Western Australia Police," RCMP Gazette, vol. 72, no. 1, pp. 22-23, 2010.

[5] E. G. Lambert, N. L. Hogan, and I. Altheimer, "An exploratory examination of the consequence of burnout in terms of life satisfaction, turnover intent, and absenteeism among private correctional Staff," The Prison Journal, vol. 90, no. 1, pp.94-114, 2010 .

[6] K. May, Government moving on disability crisis: PS 'wellness' strategy aims to take stigma out of mental illness, get workers treated faster. Retrieved June 15, 2010, from http://www.ottawacitizen.com/health/Government+moving+disability + crisis/2682893/story.html

[7] J. M. Violanti, "Dying for work: Stress and health in policing,' RCMP Gazette, vol. 71, no. 1, pp. 20-21, 2010.

[8] C. Ross, "Improving workplace health one leader at a time," RCMP Gazette, vol. 72, no. 1, pp. 7-9, 2010.

[9] A. L. Person, S. E. Colby, J. A. Bulova, and J. W. Eubanks, "Barriers to participation in workplace wellness program," Nutrition Research and Practice, vol. 4, no. 2, pp. 149-154, 2010.

[10] R. Parker, "Curbing officer obesity: Arming officers with nutritional choices," RCMP Gazette, vol. 72, no. 1, pp. 26-27, 2010.

[11] Corporate Reporting System. 2010. Offender profile. Retrieved June 15, 2010, from http://infonet/pa/corporate_e.asp\#5

[12] B. Wilkerson, "Principles of mental health: Charting a new course for the RCMP," RCMP Gazette, vol. 72, no. 1, pp. 14-16, 2010.

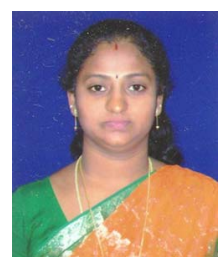

K. Santhana Lakshmi first author, has born on 27th April 1976, at Chengalpattu, Tamilnadu, India. She has completed Bachelor of Arts in History at Madras University, Chennai, Tamilnadu, India, in 1997, Master of Arts in Public Administration at Madras University, Chennai, Tamilnadu, India, in 1999, Master of Philosophy in Public Administration at Madurai Kamaraj University, Madurai, Tamilnadu, India, in 2002 and Master of Business Administration in the field of Human Resource Management at Anna University, Chennai, Tamilnadu, India, in 2006.
She is currently working as Assistant Professor in the School of Management, SRM University, Kattankulathur, Kanchipuram Dt., Tamilnadu. She was previously working in different organizations such as SRM Hotels Pvt Ltd, Chennai, Recall Total Inf. Mgmt. (Pvt.) Ltd., Chennai, Vidhya Saghar Women's College, Chennai, Karpaga Vinayaga College of Engg. \& Tech., Chennai. She has published two articles in National level journals, ten articles in International level conference proceedings and eighteen articles in National level conference proceedings.

Mrs. K. Santhana Lakshmi is a member of IGNOU scheme, moreover she is a life member of Indian Science congress. She is also member of International Economics Development and Research Center (IEDRC).

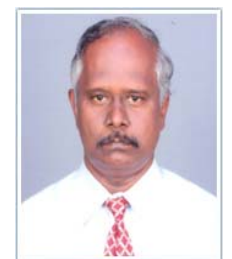

Dr.T.Ramachandran second author, has born on at, Tamilnadu, India. He has completed Bachelor Degree in Commerce at Madras University, Chennai, Tamilnadu, India by 1997 , Master Degree in Commerce at Bharadidasan University, Thanjavur, Tamilnadu, India by 1985, Master of Philosophy in Commerce at Annamalai University, Chidambaram, Tamilnadu, India by 1987, Master of Business Administration in the field of Finance Management at Madras University, Chennai, Tamilnadu, India by 1997 and He has completed Doctorate in Finance at Madras University, Chennai, Tamilnadu in 2006.

$\mathrm{He}$ is currently working as Professor in the School of Management, SRM University, Kattankulathur, Kanchipuram Dt, Tamilnadu. He was previously working as a Lecturer in Adaikalamatha college, Thanjavur, Tamilnadu. He has published six articles in National level journals, ten articles in International level conference proceedings and eighteen articles in National level conference proceedings.

Dr. T.Ramachandran is a life member of Indian Science congress. He is also member of International Economics Development and Research Center (IEDRC).

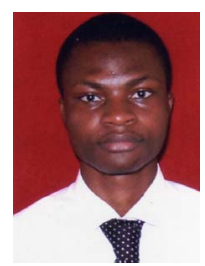

David Boohene third author, Born in Accra, Ghana on September 27th, 1985, David graduated with a Bachelors degree in Economics from KNUST, Ghana in 2008 and Masters degree in Business Administration with specializations in Hospital and Human Resource Management at SRM University, India in 2012. He is a member of Society for Human Resource Management and the Human Resource Executive Association. He has served in various capacities such as member of the Academic counseling team at All Nations University College as well as Special Assistant to the Deputy Registrar of All Nations University College. He is also the Business Development Manager of Brand Personobi, Ghana. His area of Research is in work life balance and quality assurance. He is also member of International Economics Development and Research Center (IEDRC). 